\title{
SUBSTANTIATION OF ECONOMICALLY EXPEDIENT LOCATION OF TECHNOLOGICAL STRAW PROCESSING LINE
}

\author{
Valentina Kukharets ${ }^{1}$, Rasa Cingiene ${ }^{2}$, Nataliya Savchenko ${ }^{1}$, Roman Savchenko ${ }^{1}$ \\ ${ }^{1}$ Polissia National University, Ukraine; ${ }^{2}$ Vytautas Magnus University, Lithuania \\ lidanaz@ukr.net, rasa.cingiene@vdu.lt, nataliyasavchenko2010@ukr.net, \\ rsavchenko2002@yahoo.com
}

\begin{abstract}
Plant biomass is mostly used by the agricultural enterprises for their own needs. But there is a possibility to use biomass for biofuel production. It requires the adaptation of new technical equipment that, in its turn, requires capital expenditures. In particular, it is the production of fuel pellets from straw. The combination of efforts and resources of a significant number of agricultural enterprises makes it possible to combine the financial resources for purchasing the required technological line, as well as to provide it with a necessary amount of raw materials. For example, it is expedient to locate a technological line on the production of fuel pellets from the straw with regard to the lowest transport expenses. While choosing such an enterprise, the distance from it to other enterprises (association partners), as well as the available biomass potential should be considered. The location of an enterprise which will produce biofuel should be instrumental in cutting down the expenditures. Thus, it is necessary to minimize the distance between the suppliers and the enterprise, which will result in minimization of transport costs, as well as in time expenditures that are required for organic raw material transportation. In order to achieve this target, by using the method of potential functions, it is necessary to determine the conventional points on the map of a chosen area which will supply biomass. These above mentioned points determine the centres of biomass potentials of the enterprises on the supply area. Herewith, it is expedient to make a cartogram of organic raw materials capacity, on which a circle is drawn for each enterprise and the centre of this circle coincides with the coordinates of a given enterprise centre, the area of a circle equals (at scales) the specified potential of organic raw materials. Then it is suggested to calculate the objective function value of determining the coordinates for setting a technological line of the manufacturing process at some enterprise.
\end{abstract}

Keywords: agricultural association, equipment, expenditures, potential function, agricultural enterprise, transport expenses.

\section{Introduction}

A goal of any agricultural enterprise, as a business entity, is to earn profit [1]. Switching to a completely innovative approach regarding the production process will boost competitiveness and profitability of business entities. One of the ways of raising income and introducing innovative approaches is using agricultural biomass for generating energy [2].

At the agricultural enterprises by-production of the productive work of organic raw materials of vegetable origin (straw) is used for their own needs. But, taking into consideration some innovative tendencies of using this kind of manufactured agricultural products, there is an opportunity to use the straw for generating energy [3; 4]. For this purpose, it is necessary to use new technical equipment, that implies large investments. Paper [5], for instance, describes some future-oriented technologies of biological straw processing into gas oil, but it has been admitted that they require substantial capital expenditures. Paper [6] considers the technologies of thermo-chemical straw processing for receiving fuel and shows their effectiveness in reducing the emission of greenhouse gases. But using these technologies also implies investing substantial financial resources.

Biomass transportation expenses, due to its physical characteristics, make up a substantial part in the cost of generated energy [7]. That is why one of the ways of reducing the cost of introducing new technologies of the straw processing is logistics [8]. Such ways of biomass processing like baling, pelleting, pyrolysis or gasification are used to reduce the logistic expenses in the process of using straw $[9 ; 10]$.

Besides, the investigations show that the effectiveness of the technology of biomass processing increases when the technological line productivity increases as well $[7 ; 11]$. That is, the higher volume of biomass is transformed into energy, the higher is the efficiency factor of the equipment which is a part of the technological line. Great amount of biomass is required in order to provide a continual 
operation of such lines. But small and medium-size agricultural enterprises cannot provide sufficient volumes of biomass.

High cost of equipment for technological lines on biomass processing into fuel makes it necessary to combine efforts and resources (raw material resources and financial ones) of the agricultural enterprises for effective biofuel production. Pooling of financial resources of the agricultural enterprises raises a possibility of purchasing a necessary technological line. Pooling of raw materials resources of the agricultural enterprises gives a chance to provide a technological line on biofuel production with a necessary amount of raw materials.

It is expedient to locate a technological line on biofuel production at a point (geographical) with the least traffic volume, that will considerably reduce logistics costs. It is necessary to take into consideration the distance from all enterprises (association members) to this point, as well as to estimate the potential of the available biomass and the seasonal patterns of receiving raw materials.

Therefore, we will focus on transport expenses (logistics) in our further research.

\section{Materials and methods}

When choosing a point for installing a technological line on biofuel production, it is necessary to minimize transportation, thus the transportation costs and time consumption used on raw materials transportation will be minimal. The authors suggest to determine some reference points on the map of a chosen area (from which organic raw materials will be supplied) by applying the method of potential functions $[12 ; 13]$. The above mentioned points determine the centres of organic raw material potentials of the enterprises. They must be considered as the points of locating processing enterprises for processing organic raw materials into fuel. Herewith, it is expedient to make a cartogram of organic raw material potentials on which a circle is drawn for each enterprise, and the centre of this circle coincides with the coordinates of a given enterprise centre, the area of a circle at scales $\mu$ equals the specified potential of organic raw materials:

$$
r_{i}=\sqrt{\frac{P_{i}}{\pi \mu}},
$$

where $r_{i}$-radius of a circle, which illustrates the biomass potential at the first enterprise, $\mathrm{mm}$;

$P_{i}$ - estimated organic raw material potential at the first enterprise, $\mathrm{t}$;

$\mu$ - coefficient of concordance, $\mathrm{t} \cdot \mathrm{mm}^{2}$

The coordinates of the centre of raw material potentials are determined in a false grid system, which is marked in arbitrary style in nominal units of measure. The coordinates of the centre of raw material potentials of a supply region can be calculated by a functional equation:

$$
\sum_{i=1}^{n} \sum_{j=1}^{m} P_{r i}\left[\left(x_{i}-x_{p j}\right)^{2}+\left(y_{i}-y_{p j}\right)^{2}\right] \rightarrow \min ,
$$

where $x_{p j}, y_{p j}$-coordinates of a centre of $j$ - option regarding the installation of a technological line on biofuel production, $\mathrm{km}$;

$x_{i}, y_{i}$ - coordinates of a centre of $i$ - enterprise, which supplies raw materials, km;

$n$ - amount of enterprises which supply raw materials;

$m$ - number of options regarding the installation of a technological line.

For the option regarding the installation of one technological line of processing biomass into fuel $(m=1)$ and taking into consideration the fact that grain crop productivity on the farm enterprises varies and the annual straw potential changes, the coordinates of the centres of organic raw material potentials should be determined with due regards to possible potential fluctuations. The coordinates of technological line installation $x_{p}$ and $y_{p}$ - must be presented as functions of time:

$$
x_{p}(t)=\frac{\sum_{i=1}^{n} P_{i}(t) x_{i}}{\sum_{i=1}^{n} P_{i}(t)}, y_{p}(t)=\frac{\sum_{i=1}^{n} P_{i}(t) y_{i}}{\sum_{i=1}^{n} P_{i}(t)} .
$$


These functions describe a displacement of the centre of potentials, whose coordinate values are sequenced in discrete moments of time and form a set of points, which fill some area, which is called a dispersal zone of the centre of potentials. That is why it is necessary to introduce an additional coordinate dissipation factor $\alpha_{i}(t)$, which represents the raw material potential ratio of the i- enterprise to a total potential of organic raw materials at the same period of time:

$$
\alpha_{p}(t)=\frac{P_{i}(t)}{\sum_{i=1}^{n} P_{i}(t)} .
$$

As $\alpha_{i}(t)$ have insignificant annual fluctuations $\left(\alpha_{i}(t)\right.$-const $)$, the equation system 3 , which is used for the fixation of coordinates in which it will be expedient to locate an agricultural servicing cooperative, will look like:

$$
x_{C}=\frac{\sum_{i=1}^{n} P_{i} x_{i}}{\sum_{i=1}^{n} P_{i}}, y_{C}=\frac{\sum_{i=1}^{n} P_{I} y_{i}}{\sum_{i=1}^{n} P_{i}} .
$$

where $x_{c}, y_{c}$-coordinates where the technological line will be installed, $\mathrm{km}$.

The distance $L$ from the centre of organic raw material potentials to the enterprises-suppliers must strive to a minimal value:

$$
L=\sqrt{\left(x_{i}-x_{c}\right)^{2}+\left(y_{i}-y_{c}\right)^{2}} \rightarrow \min
$$

The coordinates where the technological line must be installed, must provide a minimal value for $L$.

The approbation of the method of potential functions was carried out on the example of the agricultural enterprises of Zhytomyr oblast, Ukraine, which are similar to the investment prospects. The potential values of the available straw for the last 5 years, as well the mean values were used. The investigations in which the methods of determining the available straw potential which offset the demand of animal breeding for the straw, as well as for the restoration of the organic matter balance $[3 ; 14]$ were used in order to find the available straw potential. As follows from the research, from $40 \%$ to $50 \%$ of all available straw (depending on the yield and weather conditions) can be used for its processing into biofuel.

\section{Results and discussion}

A strategy of horizontally integrated branch diversification $[3 ; 15]$ has been offered for the chosen enterprises. The strategy envisages the formation of a new manufacturing facility inside the agricultural enterprise, which will differ from the manufacturing facilities of generally accepted economic sectors (plant growing and cattle breeding) in final product, means of production, technology and the opportunity to use the agricultural products of one economic sector for the productive consumption in other sectors. The production of straw pellets [16] can be an example of such kind of suggested diversification. Herewith, the raw material for pellets manufacturing has already been produced by the enterprises.

When applying a suggested strategy, it is necessary to take into account the correlation between the investment volume and changes in the potential gains. Differences in the investment attractiveness of agricultural production of different regions of Ukraine are caused by the difference in soil quality, in fixed and current assets of the enterprises, in the profitability in different regions. That is why, the approbation of a method of potential functions will be conducted on the example of agricultural enterprises of Zhytomyr oblast of Ukraine which are similar to their investment attractiveness. The calculation for installing a technological line on the production of fuel pellets from straw will be made. The initial data for determining the location coordinates of installing the technological line on biofuel production are given in Table1.

An available volume of straw which will be processed into fuel pellets is shown for each enterprise in a form of circles (Table 1). Having substituted the required values from Table 1 into formula 5, we 
will receive the coordinates of the centre of biomass potentials in which it will be expedient to install a technological line for biomass processing into biofuel:

$$
x_{C}=\frac{\sum_{i=1}^{n} P_{i} x_{i}}{\sum_{i=1}^{n} P_{i}}=\frac{90144.9}{7197.9}=12.5, \quad y_{C}=\frac{\sum_{i=1}^{n} P_{I} y_{i}}{\sum_{i=1}^{n} P_{i}}=\frac{156014.4}{7197.9}=21.7 .
$$

The coordinates of the technological line location (point A in fig. 1) equal $x_{c}-12.5 \mathrm{~km}, y_{c}-21.7 \mathrm{~km}$, in our case.

The location of the technological line on biomass processing into fuel in a point with marked coordinates will allow to receive a minimal volume of transportation, as well as to reduce logistic expenses.

\section{Data necessary for determining the location coordinates of installing the technological line on biofuel production}

\begin{tabular}{|c|c|c|c|c|c|c|c|}
\hline \multirow[t]{2}{*}{$\begin{array}{c}\text { Name of } \\
\text { agricultural } \\
\text { enterprise }\end{array}$} & \multirow{2}{*}{$\begin{array}{l}\text { Available } \\
\text { amount of } \\
\text { straw for } \\
\text { manufact- } \\
\text { uring fuel } \\
\text { pellets }\left(P_{i}\right), t\end{array}$} & \multirow[t]{2}{*}{$\begin{array}{l}\text { ID of the } \\
\text { enterprise }\end{array}$} & \multicolumn{2}{|c|}{$\begin{array}{c}\text { Location } \\
\text { coordinates of } \\
\text { the agricultural } \\
\text { enterprise, } \mathbf{k m}\end{array}$} & \multicolumn{2}{|c|}{$\begin{array}{l}\text { Total transportation } \\
\text { volume with respect } \\
\text { to the axis, } t \cdot \mathbf{k m}^{-1}\end{array}$} & \multirow{2}{*}{$\begin{array}{c}\text { Radius of } \\
\text { circles which } \\
\text { characterise } \\
\text { the available } \\
\text { straw } \\
\text { potential, } \\
\text { mm* } \\
r_{i} \\
\end{array}$} \\
\hline & & & $x_{i}$ & $y_{i}$ & $P_{i} x_{i}$ & $\boldsymbol{P}_{i} \boldsymbol{x}_{i}$ & \\
\hline PE "Impak" & 2035 & 1 & 12.8 & 12.8 & 26042 & 26087 & 56 \\
\hline LLC “CV Spika” & 1149 & 2 & 11.0 & 25.0 & 12618 & 27586 & 42 \\
\hline $\begin{array}{c}\text { ALLC } \\
\text { "Starokotel- } \\
\text { nianske" } \\
\end{array}$ & 973 & 3 & 21.5 & 27.3 & 20884 & 26548 & 38 \\
\hline POCV "Nadia" & 873 & 4 & 0.8 & 20.3 & 737 & 17702 & 36 \\
\hline ALLC "Hliborob" & 717 & 5 & 5.7 & 30.2 & 4110 & 21663 & 33 \\
\hline $\begin{array}{c}\text { PE } \\
\text { "Yaropovychi" }\end{array}$ & 485 & 6 & 27.7 & 25.0 & 13457 & 12110 & 27 \\
\hline $\begin{array}{c}\text { ALLC } \\
\text { "Dobrobut" }\end{array}$ & 374 & 7 & 5.7 & 30.4 & 2139 & 11371 & 24 \\
\hline POCV "Colos" & 306 & 8 & 15.2 & 16.4 & 4633 & 5027 & 22 \\
\hline $\begin{array}{c}\text { ALLC } \\
\text { "Ivankivske" }\end{array}$ & 287 & 9 & 19.3 & 27.6 & 5526 & 7920 & 21 \\
\hline Sum & 7198 & - & - & - & 90145 & 156014 & - \\
\hline
\end{tabular}

* coefficient of concordance $0.21 \mathrm{t} \cdot \mathrm{mm}^{-2}$

The circles on the cartogram, which show the straw potential at some enterprises, will allow to give a visual assessment, as the point of installing a technological line is the centre of the circle mass limited by the rounds.

Pooling financial and raw material resources of the agricultural enterprises will enable the enterprises to win fresh market segments, to introduce closed productive cycles, as well as to increase the profit level.

The drawback of the suggested method of substantiating the location of the technological line is the fact that it does not take into consideration the availability of a road net. But, as the authors think, the road net consideration will not change the coordinates of the technological line installation. But it requires additional investigations, therefore, the further studies of the authors will be focused on considering the road net configuration as well as on the location area of the final consumers of the manufactured production.

Roughly, the mean value of straw transportation cost is $0.15 \mathrm{EUR} \cdot \mathrm{t}^{-1} \cdot \mathrm{km}^{-1}$. The availability of a road net is considered (Fig. 2). The straw transportation expenses under different variants of the technological line location are calculated (Fig. 3). 


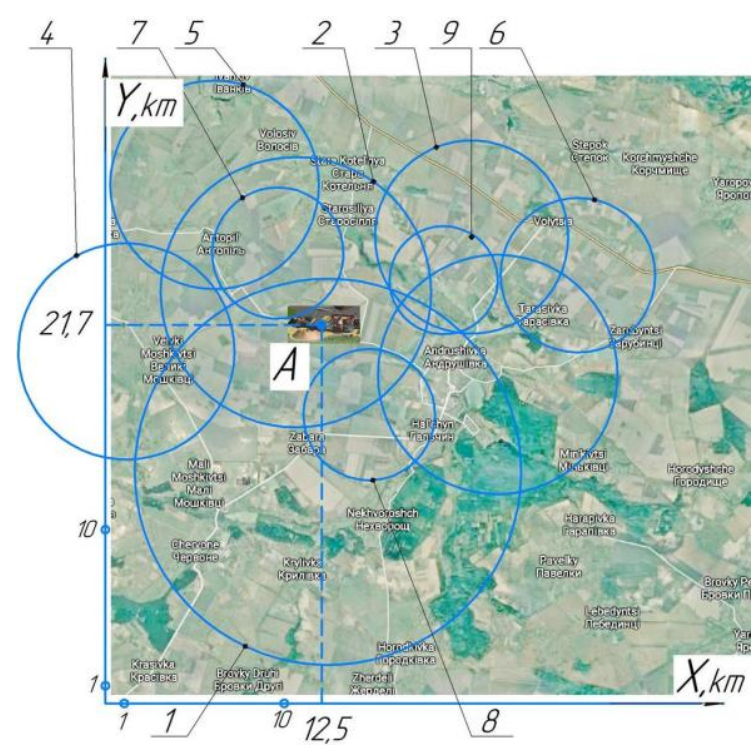

Fig 1. Cartogram of straw potentials available for processing into fuel pellets (IDs are given in Table 1)

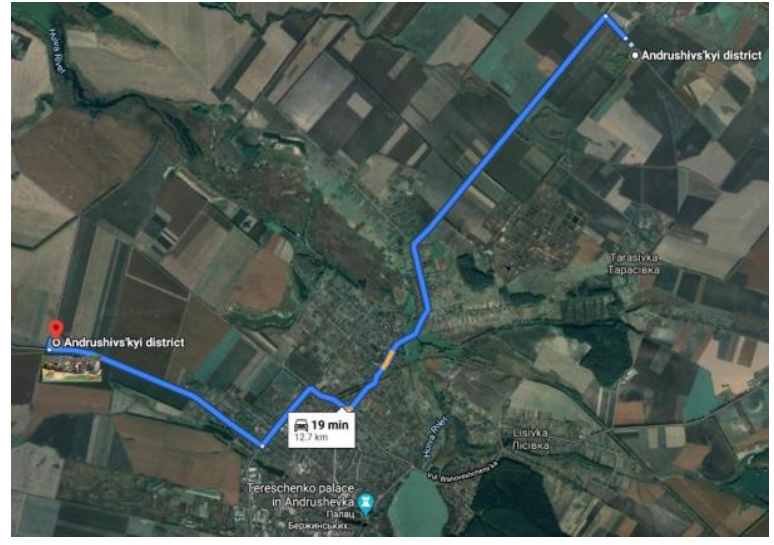

Fig. 2. Example of determining the distance between PE "Yaropovychi" and the technological line (the line is installed according to the received coordinates) with regard to a road net (using Google Maps)

The calculations show that the lowest transport expenses are observed when the technological line is located according to the received coordinates and amount to $9800 \mathrm{Eu}$ a year (under the average straw transportation cost of $0.15 \mathrm{EUR} \cdot \mathrm{t}^{-1} \cdot \mathrm{km}^{-1}$ ). As a variant, a technological line can be installed at LLC "CV Spika", herewith, transportation cost will increase up to 10200 Eu a year (by 3.6\%) but the expenses on the technological line installation can be much lower due to using the available infrastructure.

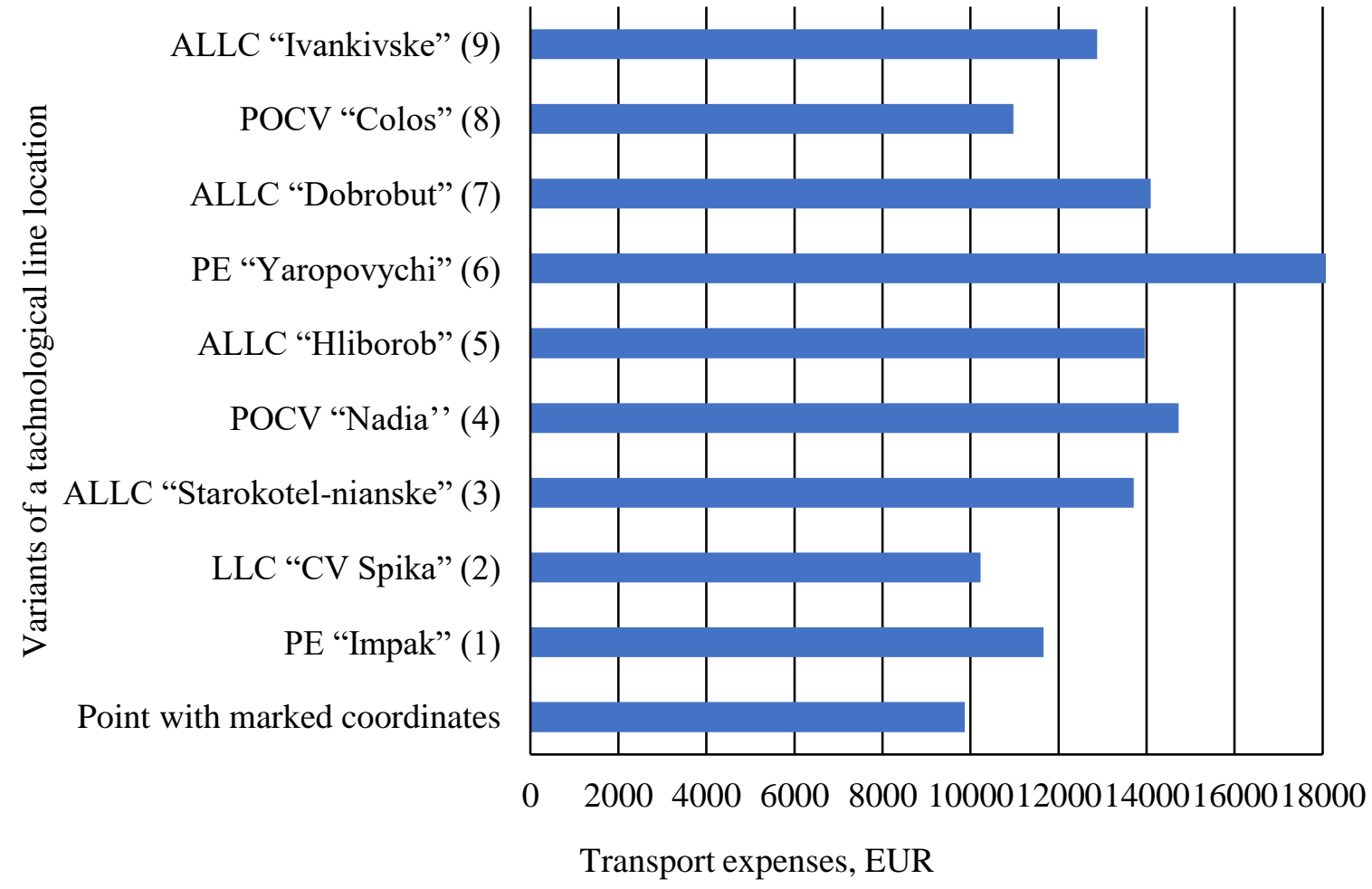

Fig. 3. Straw transportation expenses under different variants of the technological line location 
The suggested method can be used for substantiating the location of a processing line for a wide range of the agricultural biomass.

\section{Conclusions}

1. High cost of equipment for technological lines for biomass processing into fuel makes it necessary to combine efforts and resources (raw material resources and financial ones) of the agricultural enterprises for effective biofuel production. Pooling financial resources of agricultural enterprises makes it possible to purchase the required technological line. Pooling raw material resources of agricultural enterprises makes it possible to provide a technological line on biofuel production with the necessary amount of raw materials.

2. When choosing a point for installing a technological line on biofuel production, it is necessary to minimize transportation that will result in lower transportation expenses and time consumption. With this in mind, it is necessary to determine the centre of biomass potential of the enterprises of the biomass supply area. This centre must be considered as the point of location of the technological line on biomass processing into fuel.

3. The location of the technological line for biomass processing into fuel at a point with determined coordinates (center of biomass potentials) will make it possible to have minimal volume of transportation and to reduce logistic expenses. It will enable the enterprises to win fresh market segments, to introduce close productive cycles, as well as to increase the profit level.

4. We suggest to install a technological line at LLC "CV Spika", herewith, the transportation cost will amount to $10200 \mathrm{Eu}$ a year (by 3.6\% lower than in case when the technological line is installed according to the received coordinates). Herewith, the expenses on a technological line installation will be much lower due to using the available infrastructure.

\section{References}

[1] Steiner A., Teasdale S. Unlocking the potential of rural social enterprise. Journal of Rural Studies, vol. 70, 2019, pp. 144-154, DOI: 10.1016/j.jrurstud.2017.12.021.

[2] Debnath D., Giner C. Chapter 4 - Interaction between biofuels and agricultural markets. Bioenergy and Food Security, Academic Press, 2019, pp. 61-76, DOI: 10.1016/B978-0-12-803954-0.000048.

[3] Golub G., Skydan O., Kukharets V., Yarosh Y., Kukharets S. The estimation of energetically selfsufficient agroecosystem's model. Journal of Central European Agriculture, vol. 21(1), 2020, pp. 168-175, DOI: 10.5513/JCEA01/21.1.2482.

[4] Golub G., Kukharets S., Yarosh Y., Zavadska O. Structural models of agroecosystems and calculation of their energy autonomy. Engineering for rural development, vol. 18, 2019, pp. 13441350, DOI: 10.22616/ERDev2019.18.N073.

[5] Ghosh S., Chowdhury R., Bhattacharya P. Sustainability of cereal straws for the fermentative production of second generation biofuels: A review of the efficiency and economics of biochemical pretreatment processes. Applied Energy, vol. 198, 2017, pp. 284-298,

DOI: 10.1016/j.apenergy.2016.12.091.

[6] Sharma A., Singh G., Arya S. Biofuel from rice straw. Journal of Cleaner Production, 2020, 124101, DOI: $10.1016 /$ j.jclepro.2020.124101.

[7] De Jong S., Hoefnagels R., Wetterlund E., Pettersson K., Faaij A., Junginger M. Cost optimization of biofuel production - The impact of scale, integration, transport and supply chain configurations. Applied Energy, vol. 195, 2017, pp. 1055-1070, DOI: 10.1016/j.apenergy.2017.03.109.

[8] Awais F., Flodén J., Svanberg M. Logistic characteristics and requirements of Swedish wood biofuel heating plants, Renewable and Sustainable Energy Reviews, vol. 138, 2021, 110650, DOI: $10.1016 /$ j.rser.2020.110650.

[9] Albashabsheh N., Heier Stamm J. Optimization of lignocellulosic biomass-to-biofuel supply chains with densification: Literature review. Biomass and Bioenergy, vol 144, 2021, 105888, DOI: 10.1016/j.biombioe.2020.105888.

[10] Wang Z., Wang Z., Xu G., Ren J., Wang H., Li J. Sustainability assessment of straw direct combustion power generation in China: from the environmental and economic perspectives of straw 
substitute to coal. Journal of Cleaner Production, vol. 273, 2020, 122890. DOI: 10.1016/j.jclepro.2020.122890.

[11] Kheybari S., Rezaie F., Naji S., Najafi F. Evaluation of energy production technologies from biomass using analytical hierarchy process: The case of Iran. Journal of Cleaner Production, vol. 232, 2019, pp. 257-265, DOI: 10.1016/j.jclepro.2019.05.357.

[12] Yazdani M., Chatterjee P., Pamucar D., Chakraborty S. Development of an integrated decision making model for location selection of logistics centers in the Spanish autonomous communities. Expert Systems with Applications, vol. 148, 2020, 113208, DOI: 10.1016/j.eswa.2020.113208.

[13] Hussien B., McLaren R. Real-time robot path planning using the potential function method. Automation in Construction, vol. 2(3), 1993, pp. 241-250, DOI: 10.1016/0926-5805(93)90044-x.

[14] Ferrari G, Pezzuolo A, Nizami A-S, Marinello F. Bibliometric Analysis of Trends in Biomass Processing for Bioenergy Research. Energies. 2020; vol. 13(14), 3714. Doi:10.3390/en13143714.

[15] Kim H., Park M., Lee S. Do vertically and horizontally integrated firms survive longer? The case of cable networks in Korea, Information Economics and Policy, vol. 39, 2017, pp. 84-93, DOI: 10.1016/j.infoecopol.2017.02.003

[16] Pradhan P., Mahajani S., Arora A. Production and utilization of fuel pellets from biomass: A review. Fuel Processing Technology, vol. 181, pp. 215-232, DOI: 10.1016/j.fuproc.2018.09.021. 